\title{
Reliability, Validity, and Dimensions of SEM-based Sport Tourism Risk Perception Scale
}

\author{
Gang Li \\ College of P.E., Shandong University of Finance and Economics, Jinan Shandong \\ lg0224shi@163.com
}

\begin{abstract}
This study utilizes available legal literature, questionnaire surveys, mathematical statistics, and other research methods to establish a risk perception analysis based on prior studies by Rose (1977), Joeoby and Kaplan (1972), Peter and Tarpey (1975), Stone and Gronhuang (1993), and other foreign scholars. Financial risk, information risk, social cognitive risk, liability risk, intellectual risk, functional performance risk, psychological risk, and 31 items of the sports tourism risk perception are employed to form an inspection primer and high-order sports tourism risk perception structural equation model (SEM).
\end{abstract}

Keywords: sports tourism; risk perception; scale; SEM

\section{Introduction}

Beginning in the mid-1990s, a global environment for sports and sport-related tourism has grown dramatically in popularity, shaped by demand for fitness, entertainment, leisure, and travel. Sports and sports tourism have become an essential part of the lives of many in many countries across the world. Statistics suggest that amateur alpine skiers, for example, now number 25 million worldwide, and that the figure practically doubles when including those who travel occasionally to ski resorts. Golf enthusiasts spend 6-8 days per month on average in nearby cities to tee off, and 10-16 days traveling to farther away courses; golf consumption per capita sits at the 300-340 mark. Though the appeal for sports and sports tourism is strong, many potential consumers in this area are unwilling or unable to travel, which restricts further expansion of the market. Accurate perception and methods of precisely measuring perceptions of risk related to sports tourism, including surveying cognitive risk associated with participating in sports tourism, has important economic implications.

\section{Definition of Sports Tourism Risk Perception}

Risk perception is a philosophical concept, fundamentally speaking, that includes knowledge and ideologies related to the perceiver's objective surroundings. Risk perception is also a psychological concept, however, as first suggested by Raymond Bauer of Harvard University (Bauer, 1960). According to Bauer, consumer purchase behavior is controlled to some extent by risk perception, the results of which are measurably positive or negative. Consumer purchase decisions involve some amount of uncertainty, which indeed relates to the original concept of risk perception. If extended to the concept of sports tourism, risk perception is the consumer understands of the uncertainty inherent to participation, financial and otherwise, in sport-tourism-related activities. What exactly, then, is the nature of that uncertainty, and what specifically does it include?

Notable studies on risk perception post-1960 include Joeoby and Kaplan's (1972), which divided consumer risk perception into the following five factors: financial risk (the 
value of the product does not balance the cost functional performance risk (the product cannot be used or does not provide the expected effect,) physical risk (using the product results in injury,) and social-psychological risk (the product damages the consumer's selfimage or perceived reputation.) Consumers query their willingness and ability to purchase products of varying quality, availability, and use. Peter and Tarpey (1975) proposed a sixth factor - time risk, that is, uncertainty regarding loss of time or effort in the process of purchasing or using the product. To summarize, the concept of consumer risk perception has become complex and multivariate by definition; it is characterized by economic, functional, physical, social-psychological, and time risk factors. This study, based on previous studies by Rose (1971), Joeoby and Kaplan (1972), Peter and Tarpey (1975), Stone and Gronhaug (1993), and other foreign scholars, proposes various perceived risk dimensions and applies them to sports tourism. The initial risk perception includes economic, information structural equation model, social perception, responsibility, knowledge, functional, and psychological risk factors-seven dimensions and 31 items are included in the proposed sports tourism risk perception scale, which was established in effort to measure consumer risk perception (and its intensity) regarding sports tourism product and service purchases. The Likert five point scale met structural equation model is employed, where each item is formed as a question with five possible answers from "very consistent with" (5 points) to "very inconsistent with" (1 point), as explained in detail below.

\section{Research Objectives and Methods}

\subsection{Research Location}

This study was conducted in Jinan, China. Study respondents ranged in age from 18-60 years, with incomes typical of urban occupational groups, including students and retired individuals.

\subsection{Sampling Methods}

Due to inevitable systematic sampling error, the distribution of the actual sample was slightly different than the ideal distribution. As shown in Table 1, the actual sample numbers were 282 respondents in Beijing, 259 in Zhengzhou, 184 in Jining, and 118 in Guiyang. Our analysis of variance showed that the differences between the four cities sampled were not significant in any dimension of risk perception, so they formed a representative sample as a whole. The effectiveness rate was $99.1 \%$, where 843 valid questionnaires and 7 invalid questionnaires were collected. The total response rate was $96.9 \%$, where 27 people refused the survey and 870 participated.

Table 1. Sampling Distribution of different class Distinctions

\begin{tabular}{|c|c|c|c|c|c|}
\hline & Beijing & Zhengzhou & Jinan & Guiyang & Total \\
\hline Employment Figure/million & 717.4 & 509.1 & 407.9 & 223.6 & 1858 \\
\hline Employment Proportion/\% & 38.6 & 27.4 & 22.0 & 12.0 & 100 \\
\hline Sample Number/person & 282 & 259 & 184 & 118 & 843 \\
\hline Sample Proportion/\% & 33.5 & 30.7 & 21.8 & 14.0 & 100 \\
\hline Number of transportation, postal, and power workers & 60 & 58 & 43 & 31 & 192 \\
\hline $\begin{array}{l}\text { Number of manufacturing, construction, and mining } \\
\text { workers }\end{array}$ & 22 & 21 & 15 & 14 & 72 \\
\hline Number of culture, health, and sports workers & 22 & 21 & 15 & 14 & 72 \\
\hline Number of government and civil servants & 41 & 34 & 29 & 13 & 117 \\
\hline $\begin{array}{l}\text { Number of education, scientific research, and technical } \\
\text { service workers }\end{array}$ & 39 & 35 & 29 & 11 & 114 \\
\hline $\begin{array}{l}\text { Number of wholesale and retail, catering and leisure, and } \\
\text { service workers }\end{array}$ & 30 & 26 & 18 & 7 & 81 \\
\hline Number of computer, finance, and real estate sales workers & 70 & 58 & 39 & 28 & 195 \\
\hline Total workers & 282 & 259 & 184 & 118 & 843 \\
\hline
\end{tabular}

Source: China Regional Economic Yearbook, 2013 


\subsection{Sample Characteristics}

To accurately reflect the overall characteristics of the sample, demographic variables and their respective distributions were also analyzed. Men, at 468 in number, accounted for $55.5 \%$ of the sample, women accounted for the remaining $44.5 \%$. Respondents under the age of 30 accounted for $32.7 \%$ of the total, those aged $31-40$ accounted for $44.1 \%$, 41 50 year-olds were $17.4 \%$, and $50+$ year-olds accounted for $5.8 \%$ of the total. Respondents with incomes less than $3000 \mathrm{RMB} /$ month were $21.0 \%$, 3001-5000 RMB were 45.6\%, and 5001-7000 RMB were $19.6 \%$ and $7001 \mathrm{RMB}$ or above were $13.8 \%$ of the total. Respondents with a high school education level accounted for $7.5 \%$, junior college for $16.4 \%$, undergraduate for $43.4 \%$, and graduate-level or above for $32.7 \%$ of the total.

In short, the age, income, and education level distributions of respondents were reasonable; the respective coefficients of skewness were $0.628,0.446$, and 0.67 , and Kurtosis coefficients were $0.215,0.654$, and 0.238 , respectively. (Coefficient values below 1 are similar to normal distribution.) According to previous research (Chiou, 2009), and the author's general knowledge of statistical analysis, more than $80 \%$ of any set of 5 cell expectations can be chi-square tested, so the data distribution in this study fell completely within a reasonable range.

\section{Predictive Reliability and Validity of Questionnaire}

Research assessment questionnaire reliability methods were analyzed using Cronbach's Alpha internal consistency reliability coefficient. The validity of the questionnaire was assessed by calculating the statistical relationship between the scale and its basic theoretical structure, because criteria-related validity is more decisive than content-related validity. Lundstrom (1976), Oliver (1994), and other experts have recommended using single items (item-total) for overall analysis of validity; acceptable standard validity is achieved if all test items (individual and overall) have correlation coefficients greater than 0.1.Statisticians can also confirm validity according to the biggest orthogonal rotation convergent value or factor analyses, which still involve single-and-overall correlation.

\subsection{Internal Consistency Reliability (Cronbach's Alpha)}

As shown in Table 2, the Cronbach's Alpha coefficients of the questionnaire in this study were 0.951 . According to Nunnally (1978), values greater than 0.7 are acceptable. In other words, the questionnaire distributed in this study demonstrated ideal reliability.

\subsection{Predictive Validity (Total Correlation Analysis)}

The item-total correlation analysis showed that each option on the sports tourism risk perception questionnaire had individual and overall correlation coefficients greater than 0.4, and, again, the Cronbach's Alpha coefficient is 0.951, which indicates that the questionnaire has good internal consistency (Table 2). Churchill (1979), Kohli et al. (1993), and Parasuaraman et al. (1988) all assert that to ensure satisfactory item-total correlation (single), associated with overall value below 0.4 ,

Table 2. Validity Analysis of Predictive Sport Consumer Consciousness Scale 


\begin{tabular}{|c|c|c|c|c|c|}
\hline \multicolumn{6}{|l|}{ Item } \\
\hline & MS & AV & MI & $\mathrm{SC}$ & IC \\
\hline V1 Worry about their credit is not good & 89.75 & 473.649 & .716 & .710 & .948 \\
\hline V2 Worry about mandatory spending & 89.78 & 474.819 & .715 & .809 & .948 \\
\hline V3 Worry about their providing service is not good & 89.69 & 473.351 & .757 & .843 & .948 \\
\hline V4 Exprosure to the risk of group events & 89.65 & 480.566 & .714 & .725 & .948 \\
\hline V5 Exprosure to the risk of traffic safety & 89.76 & 482.111 & .721 & .754 & .948 \\
\hline V6 Exprosure to the risk of disease hospitalization & 89.90 & 489.371 & 610 & .632 & .949 \\
\hline V7 Exprosure to the risk of luggage lost & 89.76 & 484.127 & .697 & .649 & .948 \\
\hline V8 Friends feel good about SPT & 89.80 & 492.288 & .518 & .514 & .950 \\
\hline V9 I will recommend SPT to friends & 89.65 & 492.827 & .461 & .548 & .950 \\
\hline V10 Friends are cautious about SPT & 89.75 & 486.216 & .620 & .613 & .949 \\
\hline V11 The use of SPT requires a certain body foundation & 89.80 & 483.990 & .660 & .659 & .949 \\
\hline V12 People cannot experience some complex SPT & 89.81 & 482.996 & .679 & .644 & .948 \\
\hline V13 People are prone to accidental injury during the use of STP & 89.72 & 483.851 & .683 & .666 & .948 \\
\hline V14 There is no guidance during use of STP & 89.68 & 485.116 & .618 & .622 & .949 \\
\hline V15 People receive a penalty due to improper use of STP & 89.66 & 493.751 & .515 & .505 & .950 \\
\hline V16 There is no free advice during use of STP & 89.65 & 493.223 & .512 & .493 & .950 \\
\hline V17 There is psychological pressure during use of STP & 89.73 & 496.672 & .488 & .552 & .950 \\
\hline V18 There is psychological fear during use of STP & 89.55 & 490.140 & .622 & .682 & .949 \\
\hline V19 People are nervous and fear during use of STP & 89.67 & 489.273 & .595 & .640 & .949 \\
\hline V20 There are many records and reports about luggage lost & 89.73 & 491.104 & .569 & .649 & .949 \\
\hline V21There are many records and reports about disease hospitalization & 89.76 & 492.156 & .592 & .686 & .949 \\
\hline V22There are many records and reports about traffic safety & 89.76 & 492.998 & .562 & .659 & .950 \\
\hline V23There are many records and reports about group events & 89.70 & 490.249 & .583 & .640 & .949 \\
\hline V24People are forced to bear group events by self & 89.93 & 488.977 & .605 & .664 & .949 \\
\hline V25 People are forced to bear disease hospitalization by self & 89.90 & 487.647 & .618 & .708 & .949 \\
\hline V26 People are forced to bear luggage lost by self & 89.93 & 488.431 & .600 & .726 & .949 \\
\hline V27 People are forced to bear traffic safety by self & 89.90 & 487.299 & .601 & .697 & .949 \\
\hline V28 Luggage lost are our own inability to use some skills to avoid & 89.70 & 489.486 & .565 & .671 & .949 \\
\hline V29 Traffic accidents are our own inability to use some skills to avoid & 89.66 & 492.685 & .498 & .723 & .950 \\
\hline $\begin{array}{l}\text { V30 Disease hospitalization are our own inability to use some skills to } \\
\text { avoid }\end{array}$ & 89.62 & 489.921 & .534 & .752 & .950 \\
\hline V31 Group events are our own inability to use some skills to avoid & 89.72 & 493.743 & .467 & .579 & .950 \\
\hline \multicolumn{2}{|l|}{ Standardized internal consistency reliability } & .951 & \multicolumn{2}{|c|}{ Number of items } & 31 \\
\hline
\end{tabular}

Test items that increase Cronbach's Alpha value should be deleted. As shown in Table 2 , if any one item on the questionnaire should only be deleted if the Cronbach's Alpha coefficient of its added value is not greater than. 951. The four test items V9, V17, V29, and V31 proved logical, so deleting them was not an option.

\section{Dimension Recognition of Revised Sports Tourism Risk Perception Scale}

\subsection{Exploratory Factor Analysis}

Statistical data must first undergo Bartlett sphericity testing and Kaiser-Meyer-Olkin (KMO) sampling adequacy measurement before exploratory factor analysis. According to Kaiser (1974), KMO values can be interpreted as follows: 0.9 or above is very good, .070.8 is good, 0.6-0.7 is moderate, 0.5-0.6 is poor and 0.5 or below and the factor analysis is unacceptable. The statistics gathered in this study had a KMO value of 0.942 , as well as a favorable Bartlett spherical value (0.01), indicating that the data is very well-suited to factor analysis 
Table 3. Eigen Function Values and Cumulative Contributions of Variance

\begin{tabular}{|c|c|c|c|c|c|c|c|c|c|c|c|c|}
\hline \multirow{2}{*}{$\begin{array}{l}\mathrm{Fa} \\
\text { ctor }\end{array}$} & \multicolumn{3}{|c|}{ Factor of original feature value } & \multicolumn{4}{|c|}{ Total load factor of extracted factors } & \multicolumn{5}{|c|}{ Cumulative factor of rotation } \\
\hline & $\mathrm{AE}$ & $\%$ & $\mathrm{CC} / \%$ & $\mathrm{AE}$ & $\mathrm{VC} / \%$ & & $\mathrm{CC} / \%$ & $\mathrm{AE}$ & & $\mathrm{VC} / \%$ & & $\mathrm{CC} / \%$ \\
\hline 1 & 12.66 & 40.8 & 40.860 & 12666 & 40.86 & & 40.86 & 4045 & & 15.95 & & 15.95 \\
\hline & 6 & 60 & 40.800 & 12.000 & & 0 & & 4.945 & 3 & & 3 & \\
\hline 2 & 2.893 & $\begin{array}{r}9.33 \\
4\end{array}$ & 50.193 & 2.893 & 9.334 & 3 & 50.19 & 3.505 & 8 & 11.30 & 1 & 27.26 \\
\hline 3 & 2.313 & 7.46 & 57.655 & 2.313 & 7.462 & 5 & 57.65 & 3.356 & 5 & 10.82 & 5 & 38.08 \\
\hline 4 & 1.533 & $5^{4.94}$ & 62.601 & 1.533 & 4.945 & 1 & 62.60 & 3.295 & 9 & 10.62 & 4 & 48.71 \\
\hline 5 & 1.268 & $\begin{array}{rr} & 4.09 \\
1 & \end{array}$ & 66.691 & 1.268 & 4.091 & 1 & 66.69 & 3.230 & 9 & 10.41 & 3 & 59.13 \\
\hline 6 & 1.164 & $6^{3.75}$ & 70.447 & 1.164 & 3.756 & 7 & 70.44 & 2.391 & & 7.714 & 7 & 66.84 \\
\hline 7 & 1.018 & $4^{\quad 3.28}$ & 73.732 & 1.018 & 3.284 & 2 & 73.73 & 2.134 & & 6.884 & 2 & 73.73 \\
\hline $1^{3}$ & .100 & .322 & 100.000 & & & & & & & & & \\
\hline
\end{tabular}

Further, the eigen function values of the statistical data items were greater than 1, the cumulative variance contribution rate was $73.732 \%$, and load factors were between 0.524 and 0.859 (Table 4, Table 5). The principal component analysis of the characteristic value was greater than 1, which is the standard for acceptability; according to Tabachnica and Fidell (2007), if an evaluation factor has a load above 0.45 it is generally acceptable, and if it has a load below 0.32, it is unacceptable and should be removed from the dataset. Each factor had a load greater than 0.45 in this study. To summarize, the design of each item was proven reasonable through several different methods, so the validity of the seven factors as-defined was confirmed.

Table 4. Factor-Loading Matrix Based on Varimax Orthogonal Rotation

\begin{tabular}{|c|c|c|c|c|c|c|c|}
\hline \multirow[t]{2}{*}{ Abbreviated item } & \multicolumn{7}{|c|}{ Factor component } \\
\hline & 1 & 2 & 3 & 4 & 5 & 6 & 7 \\
\hline V1 & .624 & .047 & .357 & .314 & .055 & .174 & .244 \\
\hline V2 & .745 & -.049 & .241 & .250 & .178 & .130 & .296 \\
\hline V3 & .737 & -.013 & .268 & .283 & .219 & .118 & .288 \\
\hline V4 & .804 & .138 & .186 & .155 & .126 & .148 & .174 \\
\hline V5 & .794 & .219 & .189 & .149 & .113 & .206 & .060 \\
\hline V6 & .735 & .329 & .090 & .076 & .063 & .258 & -.128 \\
\hline V7 & .660 & .282 & .294 & .054 & .162 & .218 & .047 \\
\hline V8 & .455 & .323 & .524 & -.135 & .155 & .017 & -.119 \\
\hline V9 & .194 & .278 & .750 & .054 & -.003 & -.048 & -.079 \\
\hline V10 & .208 & .143 & .723 & .211 & .084 & .090 & .235 \\
\hline V11 & .285 & .092 & .635 & .120 & .093 & .292 & .327 \\
\hline V12 & .287 & .094 & .592 & .101 & .180 & .372 & .274 \\
\hline V13 & .343 & .068 & .607 & .088 & .150 & .359 & .268 \\
\hline V14 & .313 & .100 & .367 & .163 & .102 & .696 & -.017 \\
\hline V15 & .184 & .128 & .145 & .187 & .090 & .774 & .041 \\
\hline V16 & .323 & .083 & -.010 & .035 & .161 & .676 & .279 \\
\hline V17 & .160 & .327 & .110 & -.049 & .101 & .212 & .703 \\
\hline V18 & .215 & .397 & .249 & .163 & .114 & .018 & .688 \\
\hline V19 & .156 & .536 & .246 & .098 & .120 & .080 & .540 \\
\hline V20 & .105 & .740 & .170 & .161 & .112 & .119 & .249 \\
\hline V21 & .131 & .772 & .140 & .215 & .151 & .140 & .121 \\
\hline V22 & .150 & .750 & .125 & .257 & .036 & .114 & .146 \\
\hline V23 & .194 & .637 & .136 & .441 & .096 & -.072 & .156 \\
\hline V24 & .242 & .392 & .131 & .719 & .070 & .019 & .035 \\
\hline V25 & .178 & .233 & .116 & .771 & .225 & .118 & .080 \\
\hline V26 & .168 & .221 & .043 & .744 & .337 & .177 & -.012 \\
\hline V27 & .152 & .160 & .064 & .730 & .364 & .200 & .042 \\
\hline V28 & .101 & .125 & .163 & .438 & .692 & -.003 & .124 \\
\hline V29 & .123 & .082 & .051 & .185 & .850 & .164 & .017 \\
\hline V30 & .139 & .135 & .087 & .169 & .859 & .179 & -.017 \\
\hline V31 & .170 & .053 & .064 & .125 & .791 & -.004 & .185 \\
\hline
\end{tabular}


As shown in Table 2, Factor 1 (which is comprised of items V1, V2, V3, V4, V5, V6, and V7, ) tested economic risk perception, Factor 2 (items V20, V21, V22, and V23) tested information risk perception, Factor 3 (V8 or V9, V10, V11, V12, and V13) tested social-psychological risk perception, and Factor 4 (V24, V25, V26, and V27) tested liability risk perception related to sports tourism activities. Factor 5 (V28, V29, V30, and V31) tested knowledge risk perception, Factor 6 (V14, V15, and V16) tested functional performance risk perception, and Factor 7 (V17, V18, and V19) tested socialpsychological risk perception related to sports tourism.

Table 5. Statistical Tests and Fitting Analysis of Different Sport Consumer Consciousness Models

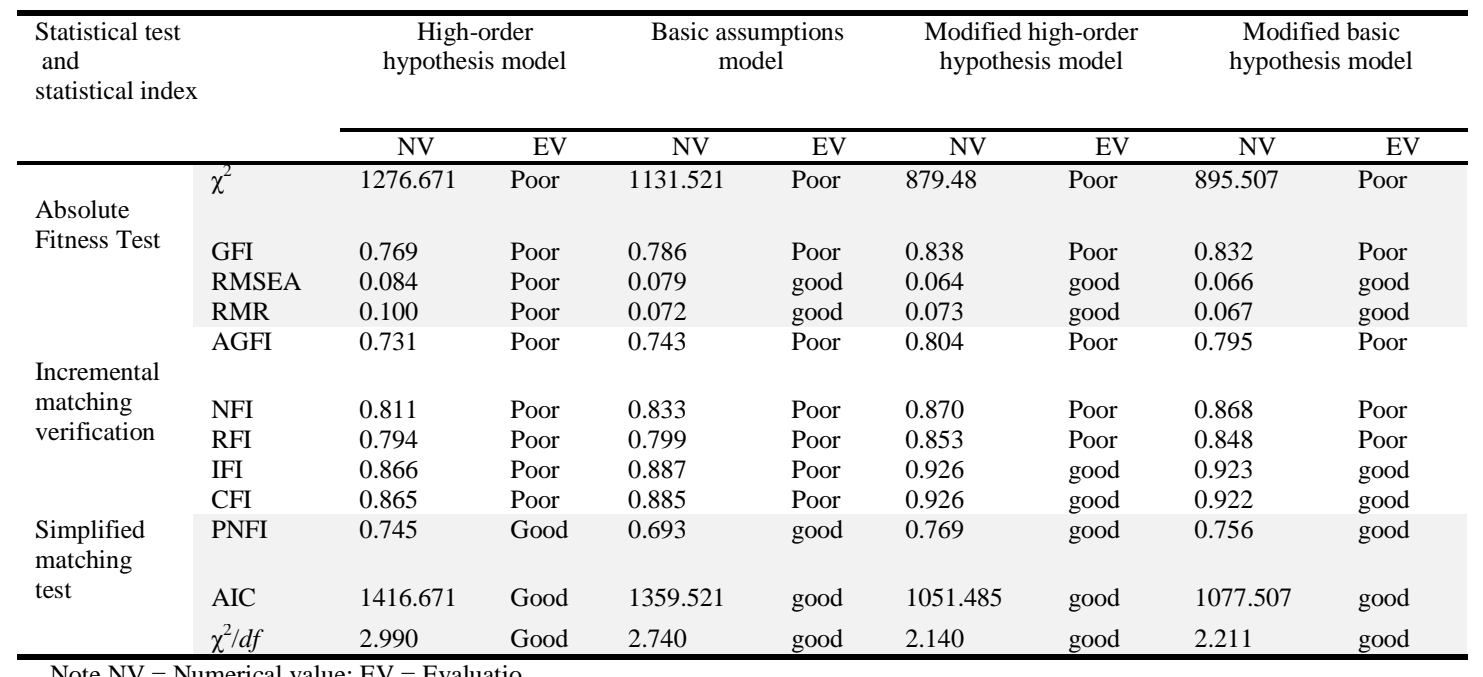

Note NV = Numerical value; EV = Evaluatio

\subsection{SEM-based Factor Analysis and Goodness of Fit Test}

Preliminary exploratory factor analysis demonstrated that overall sports tourism risk perception is comprised of 7 distinct aspects (economic, information, socialpsychological, liability, knowledge, and functional performance). Exploratory factor points, however, only apply to determining preliminary, initial structures, and are not sufficient for proving the legitimacy of the structures. For this reason, confirmatory factor analysis was subsequently employed to further validate the proposed sports tourism risk perception scale and inspect the model for goodness of fit.

There are two main types of confirmatory factor analysis: the first-order CFA model, which identifies underlying factors and tests similar sets of measured variables to determine whether the structure of the questionnaire is valid and higher-order factor analysis (HCFA), which examines fundamental potential factors for higher levels of commonality. Initial assumptions in the sports tourism risk perception model structure (the general risk perception categories discussed above), relate to a second-order modelthe entire structure clearly and intuitively reflects the perception of sports tourism-related risk. Hypotheses regarding the seven factors of the model can then reflect not only higherorder potential variables, but also the relationship between the initial, more basic factors. The proposed model benefits from facilitating basic judgments as well as more complex judgments, and, essentially, several different ways of evaluating the model.

According to research by Wang and Huang (2004) and Qiu (2003), there are many indexes that allow the statistician to assess the fit of his or her model; these indexes can be roughly split into three main categories. As shown in Table 6, the statistical indicators in this study represent certain adapted standards and critical values; the proposed sports tourism risk perception scale was analyzed for goodness of fit according to standard requirements. As shown in Table 5, according to statistical evaluation of the overall 
target, the initial set of hypotheses and the modified, higher-order hypotheses were not a good match. (The results of the incremental adaptation test indicators were especially not ideal.) In most sociological studies, however, due to the inherently high complexity of social phenomena, generally CFI, NFI, and other measured values over 0.8 are acceptable indicators of good fit, though 0.9 is more conservative (Bagozzi et al., 1988).

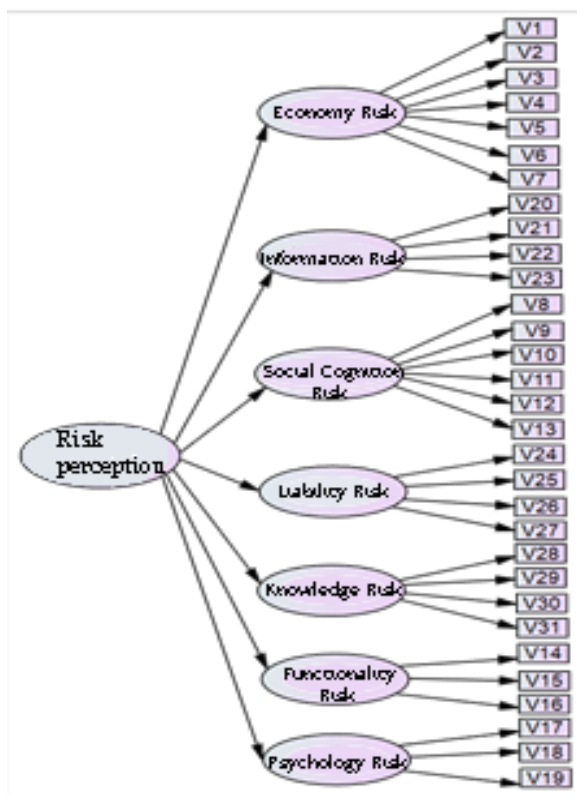

Figure 1. High-Order Sport Consumer Consciousness Model

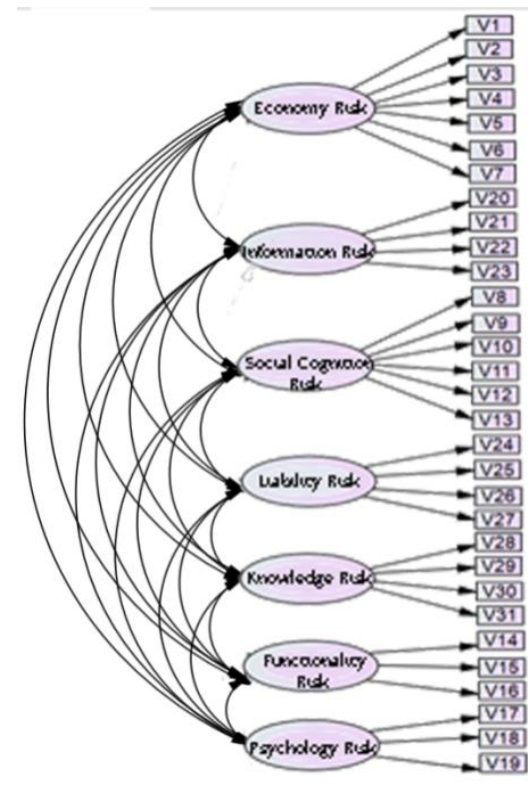

Figure 2. Junior Sport Consumer Consciousness Model

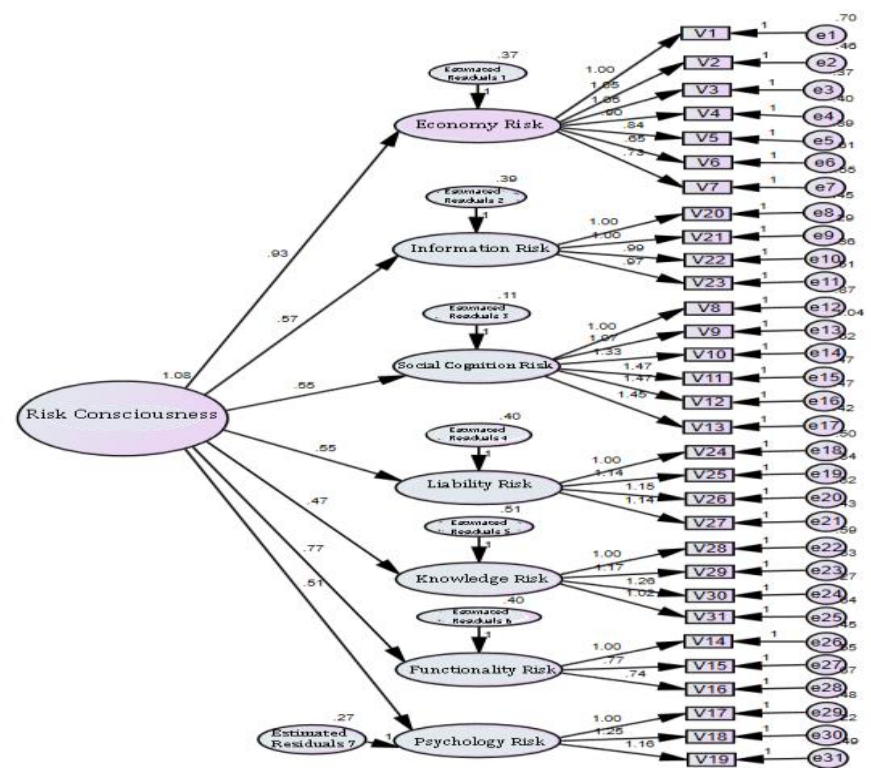

Figure 3. Amended High-Order SEM Model of Sport Consumer Consciousness 


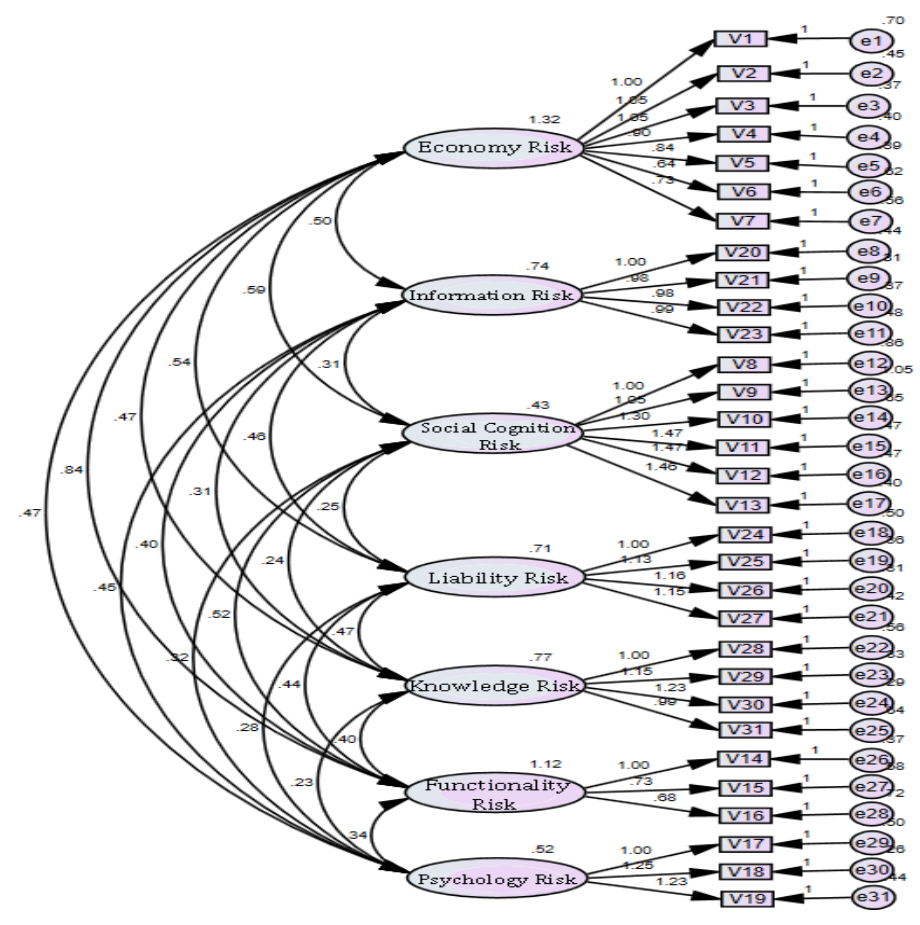

\section{Figure 4. Amended Junior SEM Model of Sport Consumer Consciousness}

As listed in Table 4 and Table 5, absolute adaptation test indicators of the higher-order hypothesis model were below critical value; goodness of fit index (GFI) values were between 0 and 1, where 0.90 or above indicates good fit. High-end assumptions of the model had average GFI value of 0.769 , which is smaller than the elementary model assumptions value of 0.786 . The mean square error (RMSEA) and root mean square error (RMR) were small, further indicating that the fitting degree is good. The data listed in Table 7 suggests that the basic hypothesis model data is less accurate than the high-order model. Each index of the high-order hypothesis model had lower incremental adaptation test values than the basic hypothesis model. Ideally, a statistical model is simple in form without sacrificing accuracy - the above analysis shows, without subsequent correction, that the high-order model and basic hypothesis model are not effective, because the highorder model does not show better fitting than the basic model.

\subsection{SEM-based Dimension Identification and Correction}

Generally speaking, all changes to the fitting index must be identified and corrected through the whole model to achieve the best possible fitting. One way to do so is to ensure a critical ratio (CR) greater than 1.96; the other is to examine the size of the revised index. The general MI index is set to 20 , so more than 20 of each variable is in the scope of the correction, and variables are generally put in order from high to low. All four of the basic perceptions in the model have reached the critical value of 1.96, they must be corrected. Two of the test items in the high-order hypothesis model were acceptable according to these standards, however. Because E6 <<--- > E7, E28 <--- > E29, E13 < -- > E14, E12 < --- > E13, E9 < --- > E31, E3 < -- > E6, E2 > E3, E2 > E5, etc., their MI values are greater than 20 and must be adjusted. For example, V2, "worried about the compulsory consumption of others" and V3, "worried that the other party is cheating..." share some amount of correlation, and should be adjusted accordingly. After adjustments were made throughout the model, the $\mathrm{CR}$ of various factors of risk perception favorably increased from 1.15 to 3. As shown in Figs. 3-6, when modifying the structural equation of the high-order model, measuring error E7 < - > allowed parameter estimates after E8 
was released that modified the structural equation of the high-order IFI, CFI, RMSEA fitting indexes considerably, at which point the model met necessary fitting standards. At initial stages of the structural equation model, three measurement errors, E17 < - > E19, E12 at 11:45 < - > E11, and E11 < - E10 were released, allowing the fitting of basic indicators to meet necessary requirements. Thus, again, the high-order structural equation model represents better fitting effects and an altogether superior model. As shown in Table 7, adjustments made at the beginning of the high-order model led to better goodness of fit than corresponding adjustments made to the basic model, so the goodness of fit of the higher-order model is better overall than the basic model.

\subsection{Analysis of Factors Influencing Sports Tourism}

The factor load values shown in Figs. 4 and 6 show where economic risk and functional performance risk are the main factors consumers consider when making decisions regarding sports tourism; the loads were 1.32 (1.31) and 1.12 (1.13), respectively. Consumers require, to this effect, professional staff to guide them through their sports activities so they feel as though their money is well-spent. Consumers also require knowledge regarding safety and training related to sports activities; this reduces economic losses due to knowledge risk. Social-psychological risk has little influence on sports tourism consumption, with only a 0.43 load. Consumers evaluate the quality of sports tourism products and services according to their own interests, which are influenced only to a small degree by those around them. Figures 3 and 5 depict the highorder model, which demonstrated that perceived risk is primarily influenced by economic and performance factors, the loads of which reached 0.93 (adjusted to 0.90 ,) which was consistent with the results of the basic model.

All in all, the current market for sports tourism consumption is characterized by consumers whose main concern is cost. Economic losses and other aspects of the market are complex and affected in nuanced ways by consumer perceptions of risk. In addition to perceived economic risks, consumers consider the risk of lacking professional guidance as they participate in sport-related activities; the functional performance risk factor had a load of 0.77 (adjusted to 0.75). Differences between the basic model and higher-order model, especially regarding the knowledge risk factor, (which had minimum load of 0.47 , adjusted to 0.45 ,) is a good example of the fact that in general, the perceived risk of sports tourism is constantly changing.

\section{Conclusion}

Sports tourism risk perception is a rather complex concept, as evidenced by the results of this study. Social processes involve a wide array of factors including the media; negative reports regarding sports tourism and sport-related activities may increase consumer perceptions of risk. Risk perception also differs for different sports, which vary in intensity - direct participation in outdoor sports, for example, carries higher risk in general than attending a sporting event as a spectator. The level of risk perceived in each dimension (knowledge, functional, and psychological versus economic, informationrelated, and liability-related,) also varies. Future research on the subject should focus on differences in perceived risk according to different sports, and attempt to establish universal measurement standards accordingly.

The sports tourism risk perception scale proposed in this study, though imperfect did successfully identify various dimensions of sport-related risk according to the operational definition of risk perception. In addition, the scale was established as an expression of quantifiable sport-related risk perception according to several important factors. Future research can further improve the specificity, accuracy, and efficiency of the proposed scale. 


\section{Acknowledgements}

This study was supported by the Shandong Social Science Planning Research Subject, China (No. 13CTYJ05).

\section{References}

[1] C. R. Alves, L. Pasqua, G. G. Artioli, H. Roschel, M. Solis, G. Tobias and B. Gualano, "Anthropometric, physiological, performance, and nutritional profile of the Brazil NationalCanoe Polo Team", Journal of Sports Science, vol. 30, (2012), pp. 305-311.

[2] R. P. Bagozzi, G. Zynep and J. R. Priester, "The social psychology of consumer behavior", University of Michigan, US: Open University Press, (2002).

[3] G. A. Churchill, "A paradigm for developing better measures of marketing constructs", Journal of Marketing Research, vol. 16, (1979), pp. 64-73.

[4] H. Crocket, "Foucault, flying discs and calling fouls: ascetic practices of the self in Ultimate Frisbee", Sociology of Sport Journal, vol. 32, (2015), pp. 89-105.

[5] K. Dashper, M. D. Giardina and J. Laurendeau, "Getting better: an autoethnographic tale of recovery from sporting injury”, Sociology of Sport Journal, vol. 30, (2013), pp. 323-339.

[6] N. Foretić, N. Rogulj and V. Papić, "Empirical model for evaluating situational efficiency in top level handball", International Journal of Performance Analysis in Sport, vol. 13, (2013), pp. 275-293.

[7] J. L. Fisette, "The marathon journey of my body-self and performing identity", Sociology of Sport Journal, vol. 32, (2015), pp. 68-88.

[8] J. Garcia-Pallares, M. Garcia-Fernandez, L. Sanchez-Medina and M. Izquierdo, "Performance changes in world-class kayakers following two different training periodization models", European Journal Applied Physiology, vol. 110, (2010), pp. 99-107.

[9] C. Goumas, "Modelling home advantage in sport: A new approach", International Journal of Performance Analysis in Sport, vol. 13, (2013), pp. 428-439.

[10] L. B. Kaplan, G. I. Szybillo and J. Jacoby, "Components of perceived risk in product purchase: a cross validation", Journal of Applied Psychology, vol. 3, (1974), pp. 287-291.

[11] H. F. Kaiser, “An index of factorial simplicity", Psychometrka, vol. 39, (1974), pp. 31-36.

[12] A. Kohli, B. Jaworski and A. M. Kumar, "A measure of market orientation", Journal of Marketing Research, vol. 3, (1993), pp. 467-477.

[13] W. J. Lundstrom and L. M. Lamont, "The development of a scale to measure consumer discontent", Journal of Marketing Research, vol. 13, (1976), pp. 153-156.

[14] J. Laurendeau, "If You're Reading This, It's Because I've Died", Masculinity and Relational Risk in BASE Jumping, Sociology of Sport Journal, vol. 4, (2011), pp. 404-420.

[15] K. E. Mille and J. H. Hoffman, "Mental Well-Being and Sport-Related Identities in College Students", Sociology of Sport Journal, vol. 26, (2009), pp. 335-356.

[16] P. Meletakos, G. Vagenas and I. Bayios, "A multivariate assessment of offensive performance indicators in Men's Handball: Trends and differences in the World Championships", International Journal of Performance Analysis in Sport, vol. 11, (2011), pp. 285-295.

[17] R. Morgans, D. Adams, R. Mullen and M. Williams, "Changes in physical performance variables in an English Championship League team across the competitive season: the effect of possession. International Journal of Performance Analysis in Sport, vol. 14, (2014), pp. 493-503.

[18] J. C. Nunnally, Psychometric Theory, McGraw-Hill, N.Y, (1978).

[19] R. L. Oliver, "Conceptual issues in the structural analysis of consumption emotion, satisfaction and vuality: evidence in a service setting", Advances in consumer research, vol. 21, (1994), pp. 16-22.

[20] J. Peter and P. Tarpey Sr., "A comparative analysis of three consumer decision strategies", Journal of Consumer Research, vol. 1, (1975), pp. 29-37.

[21] A. Parasuraman, V. Zeithaml and S. Berry, "Multiple- item scale for measuring consumer perceptions of service vuality", Journal of Retailing, vol. 64, (1988), pp. 12-40.

[22] B. Raymond, "Consumer Behavior as risk taking in dynamic marketing for a changing world", Robert S. Hancock, ed., Chicago: American Marketing Association, (1960).

[23] J. Peter and P. Tarpey Sr., "A comparative analysis of three consumer decision strategies", Journal of Consumer Research, vol. 1, (1975), pp. 29-37.

[24] F. Robert, "Living on the edge: the appeal of risk sports for the professional middle class", Sociology of Sport Journal, vol. 25, (2008), pp. 310-330.

[25] M. B. Randers, I. Mujika, A. Hewitt, J. Santisteban, R. Bischoff, R. Solano, A. Zubillaga, E. Peltola, P. Krustrup and M. Mohr, "Application of four different football match analysis systems: A comparative study", Journal of Sports Sciences, vol. 28, (2010), pp. 171-182.

[26] R. N. Stone and K. Gronhaug, "Perceived risk: further considerations for the marketing discipline", European Journal of Marketing, vol. 27, (1993), pp. 39-50.

[27] A. Sholam, "Predicting future sport consumption: The impact of perceived benefits", Sport Marketing Quarterly, vol. 9, (2000), pp. 8-14. 
[28] B. G. Tabachnick and L. S. Fidell, "Using multi-variate statistics (5th Ed)", Needham Heights, MA: Allyn and Bacon, (2007).

[29] M. K. VanRooyen, "A statistical analysis of tackling performance during international rugby union matches from 2011", International Journal of Performance Analysis in Sport, vol. 12, (2012), pp. 517530.

\section{Author}

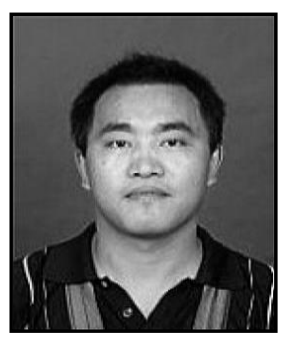

Gang Li, he was born in1976, PH.D candidate, associate professor . Main research direction is sport industry.

*Tel.: +86-531-82911941. E-mail address: lg0224shi@163.com. 
International Journal of $u-$ and e- Service, Science and Technology Vol. 10, No.3 (2017) 